\title{
Desigualdades e privação de direitos na sociabilidade capitalista e suas expressões no Brasil
}

\author{
Inequalities and deprivation of rights in capitalist \\ sociability and its expressions in Brazil
}

\author{
Helena Lúcia Augusto Chaves ${ }^{a}$ \\ (1) https://orcid.org/0000-0003-3325-0893 \\ Ana Cristina Brito Arcoverde ${ }^{a}$ \\ (D) https://orcid.org/0000-0002-8344-5536
}

Resumo: $\mathrm{O}$ artigo tem o objetivo de desenvolver abordagem conceitual sobre desigualdades, privação de direitos e questão social na sociabilidade capitalista, enfocando seu amplo espectro de expressões. Trata da realidade brasileira, destacando a mercantilização da proteção social e o desmonte das políticas públicas. Enfoca os tempos de acirramento de ultraconservadorismo nas conjunturas nacional e mundial, de privação de direitos conquistados e de regressão de estágio civilizatório alcançado.

Palavras-chave: Desigualdades. Privação de Direitos. Questão Social. Capitalismo. Brasil.

\begin{abstract}
The article aims to develop a conceptual approach on inequalities, deprivation of rights and social issues in capitalist sociability, focusing on its broad spectrum of expressions. It deals with the Brazilian reality, highlighting the commodification of social protection and the dismantling of public policies. It focuses on the intensifying times of ultraconservatism in the national and global conjunctures, deprivation of conquered rights and regression of civilization stage reached.
\end{abstract}

Keywords: Inequalities. Deprivation of Rights. Social Issues. Capitalism. Brazil. 


\section{Introdução}

1 problemática das desigualdades e privação de direitos atinge os diversos aspectos da vida social, e suscita a reflexão sobre a questão social gestada e reproduzida no âmbito do capitalismo, constituindo-se em campo de discussão permanente, visto que acompanha a trajetória histórica do modo de vida sob o capital.

Convencionou-se, ao longo dessa tajetória, mensurar as desigualdades sociais principalmente pela desigualdade econômica, que se expressa em distribuição heterogênea de renda, sendo uma ínfima parcela da população detentora de muitos bens, enquanto a maioria vive na pobreza e na pobreza extrema. Essas desigualdades afetam intensamente os países de economia periférica, nos quais a má distribuição de renda, a concentração de riqueza e a falta de investimentos em políticas sociais configuram disparidades e desequilíbrios no padrão de vida dos seus habitantes, no âmbito econômico, social, cultural ou político, configurado em seus diversos aspectos, dentre eles o educacional, o profissional, o étnico-racial, o regional e o de gênero.

De acordo com Rousseau, em texto que trata da origem da desigualdade entre os homens, publicado originalmente em 1754, há duas formas de desigualdades: a natural ou física, "que consiste na diferença das idades, da saúde, das forças do corpo e das qualidades do espírito [...]" (Rousseau, 2001, p. 38), e a desigualdade moral ou política, "que consiste nos diferentes privilégios de que gozam alguns com prejuízo dos outros, como ser mais ricos, mais honrados, mais poderosos do que os outros, ou mesmo fazerem-se obedecer por eles" (Rousseau, 2001, p. 39). Nessa formulação inicial produzida na contextualidade e contingência social do século XVIII, já são consideradas várias dimensões para esse fenômeno complexo e multifacetado, que no decorrer do processo histórico se adensou e se complexificou.

Na trajetória da sociedade capitalista, as desigualdades assumem feições diversas de acordo com as determinações políticas e sociais produzidas a cada ciclo histórico e em cada particularidade contextual, 
mas sempre estão presentes caracterizando esse modo de produção e reprodução social, configurando as diversas expressões da questão social, variando em intensidade, grau e escala em cada país. A fome, a miséria, o desemprego, a violência e as más condições de habitação, saúde, educação e inserção social são alguns dos aspectos que configuram a problemática das desigualdades e privação de direitos na sociabilidade capitalista no Ocidente, suscitando crises estrutural, social, política, econômica e humanitária sem precedentes. Para onde caminha a humanidade é uma questão que suscita reflexões e enseja a tomada de posição coletiva pelos diversos atores sociais que interagem em cada contextualidade particular e na realidade global, manipulada e conduzida pelas necessidades do capital e não pelas necessidades humanas.

Portanto, o objetivo deste artigo, tratado no primeiro tópico, é desenvolver abordagem conceitual sobre as desigualdades e privação de direitos no desenvolvimento histórico, social e político da sociedade capitalista, no qual se configuram a polêmica questão social e seu amplo espectro de expressões. No segundo tópico do artigo, desenvolve-se uma reflexão sobre a complexidade dessas desigualdades no contexto brasileiro na atualidade, destacando dados estatísticos comprobatórios da realidade factual e tecendo considerações sobre o sistema de proteção social brasileiro. O objetivo da discussão é refletir sobre esses tempos de acirramento de ultraconservadorismo nas conjunturas nacional e mundial, de privação de direitos conquistados e de regressão de estágio civilizatório alcançado.

\section{Desigualdades, privação de direitos e questão social na sociabilidade capitalista}

Desigualdades, privação de direitos e questão social, decorrentes de aspecto estrutural do capitalismo, são fenômenos inter-relacionados, desencadeados de formas múltiplas e irradiados em várias dimensões da sociabilidade. Tanto mais as desigualdades existam, persistam e/ou se 
ampliem, tanto mais privadas de direitos estarão as populações expropriadas da sociedade, e mais se reitera e torna visível a questão social por meio de suas expressões históricas - pauperismo, colonização, escravidão, opressão, conflitos identitários e étnico-raciais, preconceito, discriminação e violência contra indígenas e mulheres, racismo, repartimentos, especulação da terra, expropriações e políticas sociais excludentes, entre outras consequências. Os esforços teóricos para desvelar suas gêneses e desenvolvimentos para então construir estratégias de superação datam do século XVIII e chegam mesmo às duas décadas do presente século XXI sem consenso. Trata-se de problema estrutural, cujas investidas de enfrentamento compõem uma trajetória de modelos políticos, que não atinge a estrutura do sistema nem consegue equacionar os problemas.

Sobre o fenômeno das desigualdades, intrínseco e/ou produzido na relação entre capital e trabalho - e que, juntamente à exploração do primeiro sobre o segundo, é a base de constituição da questão social e logo dos estados de privação, levando em conta a posição do contratualista Jean-Jacques Rousseau, segundo a qual a propriedade privada, o trabalho explorado e as convenções estabelecidas produzem tais desigualdades - , podem ser observadas duas posições conflitivas então apontadas por Thomas Piketty na sua obra A economia das desigualdades (2014). A primeira agrupa liberais de direita que defendem as forças de mercado, a iniciativa individual e o aumento da produtividade como possibilidades reais de melhorar rendimentos e condições de vida dos mais desfavorecidos, devendo a ação política ser limitada a instrumentos que interfiram pouco nesse mecanismo virtuoso. A outra reúne os teóricos de esquerda que defendem as lutas sociais e políticas para combater a miséria dos mais desfavorecidos produzida pelo sistema capitalista, devendo a ação pública de redistribuição interferir intensamente no processo de produção para mudar a forma como as forças de mercado determinam os lucros apropriados pelos detentores de capitais e as desigualdades entre assalariados.

As razões para as distintas e contraditórias posições entram de certa forma em consenso quanto a princípios fundamentais de justiça social, 
ou seja, convergem a respeito da percepção de que, se as desigualdades não são de responsabilidade dos indivíduos, é "justo que o Estado tente melhorar de forma mais eficaz possível a sorte das pessoas mais desfavorecidas" (PIKETTY, 2014, p. 12).

Independentemente de tais razões, o fato é que, segundo Piketty (2014), permanece o desafio de melhorar as condições de vida dos mais desfavorecidos, seja pelos princípios de justiça social, seja pelo alargamento dos direitos a todos. Realizar uma redistribuição mais justa e eficaz ou mesmo eliminar o que lhes deu causa requer que sejam examinados os mecanismos socioeconômicos que produzem as desigualdades em cada sociedade frente a tais mecanismos de redistribuição. E esse autor faz uma análise minuciosa de tais mecanismos de redistribuição pura e de redistribuição eficaz como problema político dos conflitos entre as teorias e fatos que as distinguem e que as exploram como estratégia de enfrentamento das desigualdades oriundas dos rendimentos do capital, dos rendimentos do trabalho, das reformas e transferências sociais, dos rendimentos patrimoniais e da desigualdade contemporânea fundamental, que é a desigualdade em face do emprego. As tentativas de eliminar as determinações que dão causa à produção e à reprodução de desigualdades - propriedade privada, expropriações, trabalho explorado, políticas públicas restritivas ou mesmo focalizadas, enfim a lei geral da acumulação - saíram frustradas, requerendo outro conteúdo capaz de favorecer a reconstrução e o fortalecimento de relações de classes e lutas por uma ordem societária emancipadora.

Quanto ao fenômeno da questão social, igualmente construído nas sociabilidades capitalistas, desde o século XIX até os nossos dias, é polêmico, controverso, inconsensual, recepciona variadas interpretações e tem seu substrato nas desigualdades anteriormente elencadas, apresentando como eixo central a exploração/subordinação do trabalho pelo capital. As sociabilidades capitalistas, guardando suas particularidades, produzem desigualdades e com elas a questão social que se nos mostra latente ou manifesta. Por meio de suas expressões, essas sociabilidades constroem concepções e desenvolvem suas ações políticas às quais 
correspondem as estratégias e os instrumentos de redistribuição, ora deixando o mercado agir livremente e limitar a redistribuição por meio de impostos, transferências fiscais e políticas residuais, ora defendendo a universalidade e tentando modificar estruturalmente a forma como as forças de mercado vêm agindo e produzindo as desigualdades que são substrato da questão social.

Os estudiosos da questão social, nas ciências sociais (Castel, 2008; Rosanvallon, 1998; Telles, 2006; Ianni, 1991; Wanderley, 1997; Cerqueira Filho, 1992) e em particular no Serviço Social (Iamamoto, 2001; Netto, 2004; Pereira, 2004; Santos, 2008; Pastorini, 2010; Arcoverde, 2008) dividem-se quanto ao seu entendimento, gênese e, sobretudo, enfrentamento dos marcos do capitalismo contemporâneo globalizado. Tanto quanto as desigualdades que a lastreiam, a questão social pode ser concebida diversamente: i. "aporia fundamental sobre a qual uma sociedade experimenta o enigma de sua coesão e tenta conjurar o risco de sua fratura” e "inadaptação dos velhos métodos de gestão do social requerendo a criação pelo Estado providência ativo de um novo direito à vida, cujo consenso requereria uma nova solidariedade (Castel, 2008, p. 18; Rosanvallon, 1998, p. 38, respectivamente); ii. "Relação dialética entre estrutura e ação de sujeitos estrategicamente posicionados", embate político que se politiza nas relações entre os diferentes atores político-estratégicos - Estado, mercado e organizações da sociedade civil —, atualmente fragilizados pelo desemprego e dessindicalização (Pereira, 2004, p. 51); iii. “Síntese reflexiva do aprofundamento das desigualdades acumuladas e expressas ao longo dos diferentes modos de produção e inerente à sociabilidade capitalista" (Arcoverde, 2008, p. 116); iv. ou ainda, a questão social são "as expressões do processo de formação e desenvolvimento da classe operária e de seu ingresso no cenário político da sociedade exigindo seu reconhecimento como classe por parte do empresariado e do Estado" (Iamamoto; Carvalho, 1995, p. 77).

Dito de outra forma, a questão social traduz o processo de produção das condições materiais da vida humana sob relações histórico-econômicas de produção específica, e por isso mesmo ela é indissociável 
do processo de acumulação e dos efeitos produzidos sobre as classes trabalhadoras (Iamamoto, 2001, p. 11). É evidente que as conjunturas e mesmo as reestruturações econômico-financeiras da economia na ordem do capital global potencializadas complexificam e agravam o quadro geral das desigualdades, renovando e reproduzindo as expressões da questão social. Problematizar substancialmente a essência da questão social parece ser uma tarefa política fundamental e inadiável da e na luta de classes que gera consensos possíveis sobre as necessidades, carências, privações, subtrações, expropriações etc. para fortalecer e se fazer incluir na agenda pública a ser mediada e assegurada pelo sujeito coletivo estratégico que é o Estado.

O terceiro elemento que compõe o tema do presente texto é a privação de direitos que complexifica, reforça, recria e denuncia a produção das desigualdades, e as explicita como expressões da questão social quando se subtraem da democracia, sobretudo das mais frágeis, os direitos que formal e legitimamente já tinham sido consensuados, legitimados e inscritos nas cartas constitucionais. Não significa dizer que as cartas políticas não sejam formas modernas de garantia da lei geral de acumulação, muito pelo contrário, mas, sim, afirmá-las como formas contemporâneas de ampliação da privação de direitos, bens e serviços já consolidados.

A privação de direitos na contemporaneidade pode ser considerada, como vem tratando Boschetti (2018), modalidades atualizadas e violentas de expropriação para atender à necessidade de superlucros e superacumulação da dinâmica capitalista. Em tese, ser ou estar privado de direitos resulta da inexistência da construção burguesa dos direitos e de bens a distribuir, como em determinados períodos pretéritos, privando o sujeito protagonista do acesso e usufruto dos meios de atendimento das necessidades materiais e imateriais humanas, mas, sobretudo nas sociedades da abundância, tal expropriação resulta de decisão política deliberada de restringir, coibir, cortar e eliminar com violência ou pela via legal os direitos então conquistados por meio de lutas sociais, para gerar as bases sociais que asseguram a acumulação. Ou seja, são suprimidas as condições de subsistência das classes trabalhadoras, recolocando-as 
no processo como mercadoria ainda mais depreciada, renovando expropriações e ainda operando a própria alienação dos bens públicos.

O Estado capitalista social estrutura, com políticas sociais, uma determinada forma de cidadania, a cidadania burguesa, que conjuga direitos civis, políticos e, em especial, os direitos sociais que resultaram de lutas de classe históricas, possibilitando o alcance de emancipação política, passo inicial na trilha da emancipação humana. Como as crises são cíclicas e inerentes ao próprio capitalismo como expressão das suas contradições na busca por mais lucros e acumulação, elas provocam tensões, aceitações, reduções e perdas de conquistas à classe trabalhadora, com injunções dos compromissos firmados pelos governos com o pagamento de juros e amortização da dívida pública. E nesse caso, reafirma Boschetti (2018, p. 3), “os processos de expropriação de direitos alteram não somente o sentido e o significado do Estado social, mas também impõem à classe trabalhadora a mais perversa forma contemporânea de subsunção do trabalho ao capital".

Na contemporaneidade, a privação de direitos pelo Estado social pode ser entendida como fenômeno que ultrapassa o meramente econômico e vai mais além. Como Fontes (2018, p. 88) afirma, é a: “imposição - mais ou menos violenta - de uma lógica da vida social pautada na supressão de meios de existência ao lado da mercantilização crescente dos elementos necessários à vida [...]". A supressão de direitos, de bens e serviços públicos constitui, na verdade, renúncias ao exercício de responsabilidade dos poderes públicos para com os cidadãos em favor do sistema financeiro, limitando despesas, estimulando a mercantilização do bem ou serviço suprimido e liberando força de trabalho de tal modo a configurar o que aquela autora denomina como expropriação secundária dos recursos sociais de produção.

A extinção ou redução de direitos e de políticas sociais pela via legal contribui, na verdade, para ampliar processos de mercantilização, uma vez que reduz e reorienta a utilização do fundo público. A privação de direitos como contraface da extinção/redução de direitos termina alimentando 
a acumulação, reduz o custo com a proteção social e disponibiliza mais força de trabalho para o capital. As estratégias de redistribuição por transferências monetárias terminam sendo a política central de garantia de acesso a um mínimo rendimento, cada vez mais reduzido, para assegurar o consumo e desse modo renovar o próprio processo de reprodução ampliada da superpopulação relativa (BOSCHETTI, 2018, p. 4).

A privação de direitos é histórica e pode ser considerada uma forma contemporânea e secundária de expropriação por meio legal, ou seja: acompanha as expropriações. Os direitos sociais suprimidos pela via legal foram legitimados e regulamentados juridicamente, como é o caso emblemático e bastante visível de gestões anteriores, mas, sobretudo, das últimas decisões tomadas pelos governos brasileiros desde 2016. 0 retrocesso em direitos já estabelecidos, mas coibidos e/ou eliminados sob/por razões pouco ou nada convincentes, deixa transparecer as novas exigências da lei geral de acumulação na ordem do capital mediada pelo Estado em favor dos interesses do mercado em âmbitos local, nacional e global, com prejuízo irreversível, em curto prazo e exclusivamente, para o trabalho humano, que é o único criador de riqueza. Portanto, os fenômenos desigualdade, questão social e privação de direitos estão mutuamente implicados, são inter-relacionados e relacionados ao processo de produção e reprodução da ordem do capital e apresentam múltiplas implicações para as classes trabalhadoras.

\section{Aspectos multidimensionais das desigualdades e implicações da privação de direitos: reflexões sobre a realidade brasileira}

As desigualdades resultam das relações sociais de produção e reprodução social e estão presentes em todos os países do mundo. No contexto do neoliberalismo, a partir da década de 1980, há estudos e estatísticas que comprovam o aumento das desigualdades no mundo, mesmo em contextos nos quais as condições de pobreza foram minimizadas pelo 
alcance e abrangência das políticas sociais implementadas. A configuração desse fenômeno vai se modificando na dinâmica do processo histórico e se apresenta em múltiplas dimensões, constituindo-se em desigualdades econômicas, políticas, sociais e culturais que perpassam a sociedade contemporânea, mediadas por disparidades nas relações de gênero, características étnico-raciais, opções de credo e formações regionais, entre outras, colocando em questão a condição de cidadania, possibilitada pelo acesso aos direitos e a bens e serviços disponíveis na sociedade.

No contexto do neoliberalismo, a proteção social, que abrange ações relacionadas à garantia de bens públicos, é mercantilizável e deve ter no mercado a oferta de serviços para a satisfação das necessidades sociais. A proteção social nessa lógica é considerada uma mercadoria, por meio da qual é acionada uma rede de serviços e uma destinação orçamentária para sua operacionalização que provém de fundo público. Como mercadoria a ser vendida através da prestação de serviços privados, o fundo público se torna objeto de apropriação pelo mercado, potencializando a concentração de renda, a massificação da miséria, a negociação dos serviços básicos e a perda dos direitos de cidadania, conquistados pelas lutas sociais travadas ao longo da história.

A redução do Estado na sua função de proteção social, determinada no âmbito do neoliberalismo, intensificou o abandono e a repressão às classes trabalhadoras, inseridas ou não no mercado de trabalho, e as suas manifestações coletivas. Dessa forma, as desigualdades aumentam e, com elas, a privação de direitos civis, políticos e sociais para um grande contingente populacional. A tendência estabelecida de submeter o sul global ao julgo do imperialismo norte-americano é anunciada como único caminho propiciador de crescimento econômico. Nesse contexto, as desigualdades sociais, inerentes à ordem capitalista, são naturalizadas e apresentadas como inevitáveis, ocasionando um retrocesso histórico, configurado no desmonte das conquistas e direitos sociais resultantes das lutas históricas da classe trabalhadora. Como afirma Castel (2008), o retorno forçado do mercado autorregulado, que se constitui no atual 
processo de globalização ou de mundialização da economia, exige que os Estados-nação construam defesas mais sólidas contra o mercado, pautadas na proteção social e na garantia de direitos de cidadania. A ausência da ação estatal na promoção da proteção social contribui para a destruição das conquistas civilizatórias da humanidade.

As dimensões das desigualdades se interpenetram e se configuram também em seus aspectos particulares. Assim é que as desigualdades de renda potencializam outras desigualdades, bem como se expressam em uma gama de desigualdades que vai se configurando na impossibilidade de acessar bens e serviços. Nas sociedades capitalistas ocidentais, as desigualdades econômicas, políticas, sociais e culturais apresentam um viés de classe social, mediado pelas relações de gênero, étnico-raciais e de crença religiosa, que também se caracterizam como desigualdades e se exacerbam em contexto de expropriação de direitos, configurando-se em situações diversas de pobreza, miséria, exploração, opressão, preconceito, discriminação, injustiça, exclusão, indiferença e abandono.

No atual estágio de desenvolvimento das forças produtivas no âmbito do capitalismo, as sociedades são extremamente desiguais e assimétricas. No ranking da desigualdade social no mundo (ONU/PNUD, 2019), o Brasil está entre os sete países mais desiguais. A desigualdade social no país é marcante e afeta a maioria dos brasileiros. O percentual de pessoas na extrema pobreza atingiu, em 2018 (IBGE/PNAD Contínua, 2018), 6,5\% da população brasileira, maior patamar na série histórica, desde o início da pesquisa em 2012. Além da má distribuição de renda e da concentração de riqueza, também compõem a desigualdade social no Brasil a falta de acesso à educação de qualidade, os baixos salários, a política fiscal injusta e a dificuldade de acesso aos serviços básicos, como saúde, transporte público e saneamento básico.

O Brasil possui um longo histórico de desigualdade na distribuição de renda, como afirmam Melo e Monte (2015). As origens da concentração de renda brasileira, segundo Castro (2009), são as mais diversas e remontam ao passado colonial e escravocrata. Naquela época, a concentração da posse da terra representava a base do poder econômico, o 
que persistiu até o fim da década de 1950, refletindo-se na estrutura de poder político concentrado, autoritário e patrimonialista que se manteve de forma persistente. De acordo com Duarte, Gabriel e Stamm (2017), a má distribuição de renda posiciona o Brasil entre as nações mais desiguais do mundo, tornando esse tema alvo de estudos e debates em diferentes áreas do conhecimento. Segundo Bonelli e Ramos (1993), os primeiros trabalhos adequadamente fundamentados sobre distribuição de renda no Brasil datam do fim dos anos 1960, estimulados pela disponibilidade de dados do censo demográfico de 1960, pois, somente a partir dessa década passaram a existir estatísticas sistematizadas, fornecidas pelo IBGE, que possibilitaram, com maior segurança, a mensuração da desigualdade na distribuição da renda.

Entre os estudos que utilizaram o índice de Gini como metodologia de cálculo para medir a desigualdade de renda no Brasil, são considerados pioneiros os trabalhos de Hoffmann e Duarte (1972), Fishlow (1972) e Langoni (1973). Para esses autores, na época em que os estudos foram realizados, o país apresentava alto nível de desigualdade de renda. Apesar das diferenças metodológicas na definição de renda e dados utilizados para as décadas de 1960 e 1970, de acordo com Bonelli e Ramos (1993), ocorreu um inequívoco aumento no grau de concentração de renda nesse período, sendo que os ganhos econômicos ficaram concentrados entre os 10\% mais ricos. Na década de 1970, segundo Melo e Monte (2015), o Brasil apresentou como diferencial um crescimento econômico acelerado com expansão do processo de industrialização e urbanização, o chamado "Milagre Econômico". As políticas econômicas do período priorizaram o crescimento, argumentando que a riqueza gerada seria futuramente distribuída para a população, acarretando, para todos, benefícios sociais e econômicos. Todavia, o que se percebeu no país foi a ampliação do alto grau de concentração de renda e o aumento dos níveis de desigualdade social devidos à ausência de políticas de distribuição de renda. Ainda sobre a década de 1970, Cacciamali (2002) aponta que, durante esse rápido período de expansão no crescimento, a desigualdade manteve-se estagnada, principalmente como resultado da aceleração do processo de 
modernização da agricultura que se intensificou a partir desse decênio. No entanto, fatores externos, como a crise do sistema político associada à crise do petróleo, finalizaram o período de expansão de crescimento, dando início a um longo período de expansão da alta taxa de inflação e da desigualdade na distribuição de renda.

A década de 1980, segundo Lacerda (1994), teve um perfil distributivo ainda pior que a anterior, pois o processo de concentração de renda se agravou, principalmente a partir da segunda metade do decênio, com a persistente elevação da taxa de inflação somada a sucessivos e ineficazes planos de ajustes associados a políticas salariais adotadas no período, que ficou conhecido como a "Década Perdida”. De acordo com Ipea (2012), os anos 1980 foram marcados por intensa crise política e econômica. 0 índice de Gini do Brasil apresentou o seu ápice em 1989, ao atingir o nível recorde de 0,636, o que classificou o Brasil como o país mais desigual do mundo. Quanto à evolução da renda, ocorreu uma confluência de propensões, apresentando uma enorme redução do ritmo do crescimento da renda em relação à década anterior, que afetou sobremaneira os mais pobres. O grau de desigualdade aumentou entre as décadas de 1980 e 1990, período em que havia um processo inflacionário crônico e uma crise do sistema político com mudanças no Estado, compreendendo o fim do período da ditadura militar, iniciada em abril de 1964, e o período de transição para a democracia, demarcando o início da redemocratização (1985) e do Estado democrático de direito (1988).

Após uma década inteira de crise e planos econômicos ineficazes, os anos de 1990, segundo Melo e Monte (2015), foram caracterizados pela estabilização dos preços pelo Plano Real, que favoreceu, em parte, os estratos mais pobres da população, principalmente quanto à ampliação do poder de compra de suas rendas. Todavia, o processo de abertura econômica reduziu as margens de lucro e o nível de preços em geral, especialmente dos bens industrializados, e o ambiente de maior competitividade gerou resultados ambíguos para esses mesmos estratos sociais, de certa forma anulando os benefícios para os mais pobres. Em meados da década de 1990, observaram-se mudanças relacionadas às 
desigualdades que se confirmaram nas décadas seguintes. Os índices de distribuição de renda sofreram alterações somente a partir da metade final da década de 1990, devidas ao Plano Real.

Conforme Hoffmann (2006), a queda no índice de Gini entre 1995 e 2001 foi muito pequena, sendo que somente a partir de 2001 se observa uma clara tendência decrescente, segundo constatado pelo Ipea (2006; 2012) e por Serrano e Summa (2011). Para Cacciamali (2002), o crescimento econômico constitui uma etapa essencial, na qual a renda per capita da sociedade se eleva substancialmente. Mas a continuidade no processo de crescimento implica distribuição da riqueza, para que seja possível alcançar níveis mais elevados de desenvolvimento econômico e social. Ou seja, o conhecimento dos padrões de distribuição de renda de uma sociedade torna-se essencial para detectar se de fato o crescimento econômico está atingindo seus objetivos e promovendo distribuição de renda. E o que se observou ao longo desses anos é que a apropriação da renda nacional pelas classes mais pobres não se alterou de forma significativa, pois, sem políticas efetivas de distribuição de renda, os ganhos para os mais pobres são advindos da estabilização da economia, não representando diminuição da desigualdade.

A partir do fim da recessão de 2003, ocorre um crescimento de renda total e da renda do trabalho, em particular o emprego formal, gerando impactos cumulativos sobre os níveis de pobreza e de bem-estar social. No entanto, embora esses índices de mensuração da desigualdade na distribuição de renda tenham sofrido uma reversão a partir de 2001, a desigualdade da distribuição de renda do Brasil ainda constava entre as 12 mais altas do mundo até 2010. Segundo o Ipea (2012), em 2011 o Brasil atingiu seu menor nível de desigualdade de renda desde o início dos registros nacionais em 1960. Apesar disso, a desigualdade no Brasil permaneceu entre as 15 maiores do mundo, e seriam necessários ao menos 20 anos de políticas públicas contínuas e crescentes para atingir patamares mais justos de distribuição de renda.

Conforme dados do Ipea (2012), na primeira década do século XXI, a situação de desigualdade na distribuição de renda se reverteu, sendo 
esse desempenho atribuído à manutenção da estabilidade econômica, à promoção de políticas públicas de distribuição de renda, como o Bolsa Família, e ao aumento do salário mínimo acima da inflação. Medidas essas que se modificam a cada conjuntura, de acordo com as exigências do ideário neoliberal, a que o mundo está submetido.

Na PNAD Contínua (2018), destaca-se o abismo de renda entre os que têm mais e os que têm menos no Brasil. Quase metade da renda está nas mãos dos $10 \%$ mais ricos. Os dados indicam que o país caminha em sentido contrário à diminuição das desigualdades, devido às altas taxas de trabalho subutilizado e desemprego, ao crescimento da informalidade e à diminuição das famílias atendidas pelo Programa Bolsa Família. Segundo o IBGE (2018), cresce o desalento para a população que está excluída do mercado de trabalho pela falta de emprego ou de experiência, por ser muito jovem ou idosa. As consequências da manutenção da desigualdade social em níveis elevados marcam a sociedade brasileira com seus efeitos deletérios, afetando as condições de vida da sociedade como um todo e, principalmente, dos segmentos populacionais privados de acesso aos bens de consumo básicos. Para esses, a feição de tal fenômeno é monstruosa e avassaladora das possibilidades de existência que poderiam ter em contexto menos desigual.

Portanto, a desigualdade é um fenômeno estrutural do capitalismo, que suscita uma abordagem sistêmica (Bihr; Pfefferkorn, 2008), e precisa ser estudada, conhecida e aprofundada para tornar possível a sua compreensão e subsidiar a definição de estratégias para seu enfrentamento e superação.

\section{Conclusões}

A produção e o crescimento das desigualdades sociais são inegáveis no capitalismo, cuja lógica de acumulação de capital, estruturada na propriedade privada e na concentração da riqueza socialmente produzida pela classe trabalhadora, é apropriada privadamente, ficando a maioria 
da população sem condições dignas de sobrevivência, sem condições de reprodução da própria força de trabalho. Por isso, o Estado é fundamental na composição do capitalismo, pois é a instância competente para a realização das políticas sociais, que são direcionadas à manutenção da população ativa em condições de trabalhar. Condições essas que implicam alimentação adequada, habitação, transporte público, educação, saúde e outros setores da política social, que se destinam a garantir direitos sociais e de cidadania.

A existência, a reprodução e a ampliação dessas condições necessárias à produção e, sobretudo, à reprodução social se materializam em problemáticas que explicitam a questão social, manifesta ou latente. Quando visíveis, vêm à tona em momentos de crises da própria lei geral de acumulação, expressando que a pobreza cresce na mesma proporção do crescimento da riqueza e atinge todas as dimensões da vida.

O Brasil é objeto de reflexão por ser um dos países mais desiguais do mundo, subalternizado e submetido ao jugo imperialista, alvo de extrativismo primitivo e exploração de seus recursos para atender ao mercado internacional, em detrimento da satisfação das necessidades da maioria dos seus cidadãos. Nem mesmo o imperativo da segurança alimentar é tratado pela esfera pública com a devida atenção quanto às necessidades alimentares e nutricionais da população, que fica sempre à mercê das oscilações mercadológicas, próprias do atual estágio desse regime de acumulação, pautado nas necessidades do capital em detrimento das necessidades sociais.

A gestão ultraneoliberal e ultraconservadora que configura na atualidade o Poder Executivo no Brasil e em algumas nações do mundo evidencia mais as condições nefastas provocadas pelo intenso processo de desigualdades e pelo ostensivo ataque aos direitos sociais conquistados e assegurados na Carta Magna. Nesse contexto, destina-se à humanidade a condição da miséria, da fome, da privação de direitos em todos os seus aspectos e dimensões, agravados pela pandemia de covid-19, que, além de crise sanitária mundial, revela-se como uma crise humanitária sem 
precedentes na história da permanente crise estrutural do capitalismo ao longo de sua trajetória. Esse recorte contextual da pandemia necessitará de muitos estudos para aproximação, dimensionamento e conhecimento das desigualdades e privação de direitos, configurados nesse período, considerando o espraiamento de suas consequências na realidade vindoura.

\section{Referências}

ARCOVERDE, A. C. B. Serviço Social e questão social na globalização. Serviço Social \& Realidade, Franca, Faculdade de História, Direito e Serviço da Unesp, v. 17, n. 1, p. 109-132, 2008.

BIHR, A.; PFEFFERKORN, R. Le système des inégalités. Paris: La Découverte, 2008.

BONELLI, R.; RAMOS, L. Distribuição de renda no Brasil: avaliação nas tendências de longo prazo e mudanças na desigualdade desde meados dos anos 70. Revista de Economia Política, v. 13, n. 2, abr./jun. 1993.

BOSCHETTI, I. Supressão de direitos no capitalismo: uma forma contemporânea de expropriação? In: BOSCHETTI, I. (org.). Expropriação e direitos no capitalismo. São Paulo: Cortez, 2018.

CACCIAMALI, M. C. Distribuição de renda no Brasil: persistência do elevado grau de desigualdade. In: PINHO, Diva Benevides; VASCONCELLOS, Marco Antônio Sandoval de (org.). Manual de economia. 4. ed. São Paulo: Saraiva, 2002. v. 1, p. 406-422.

CASTEL, R. As armadilhas da exclusão. In: BELFIORE-WANDERLEY, M.; BÓGUS, L.; YAZBEK, M. C. (org.). Desigualdade e a questão social. 3. ed. São Paulo: EDUCS, 2008.

CASTRO, J. A. Evolução e desigualdade na educação brasileira. Educ. Soc., Campinas v. 30, n. 108, p. 673-697, out. 2009.

CERQUEIRA FILHO, G. A "questão social" no Brasil: crítica do discurso político dominante. Rio de Janeiro: Civilização Brasileira, 1982. (Coleção Retratos do Brasil, v. 162).

DUARTE, T. M.; GABRIEL, F. B. de A.; STAMM, C. Análise da distribuição de renda na região Sul entre 2004 e 2014. In: Congress latin american and caribbean regional sciense association international, 1.; Encontro nacional da associação brasileira de estudos regionais e urbanos, 15., 11 a 13 out. 2017, São Paulo. Anais [...]. São Paulo: FEA/USP, 2017.

FISHLOW, A. Brazilian size distribution of income. American Economic Review, Pittsburgh, v. 62, n. 2, p. 391-402, 1972. 
FONTES, V. A transformação dos meios de existência em capital - expropriações, mercado e propriedade. In: BOSCHETTI, Ivanete (org.). Expropriação e direitos no capitalismo. São Paulo: Cortez, 2018. p. 17-61.

HOFFMANN, R. Queda da desigualdade da distribuição de renda no Brasil de 1995 a 2005 e delimitação dos relativamente ricos em 2005. In: BARROS, R. P. de; FOGUEL, M. N.; ULYSSEA, G. (org.). Desigualdade de renda no Brasil: uma análise da queda recente. Brasília: IPEA, 2006. v. 1, p. 93-105.

HOFFMANN, R.; DUARTE, J. C. A distribuição da renda no Brasil. Revista de Administração de Empresas, São Paulo, v. 12, n. 2, p. 46-66, 1972.

IAMAMOTO, M. V. A questão social no capitalismo. Temporalis, Brasília: ABEPSS, 2. ed., ano 2, n. 3, p. 9-32, jan./jul. 2001.

IAMAMOTO, M. V.; CARVALHO, R. de. Relações sociais e Serviço Social no Brasil: esboço de uma interpretação histórico-metodológica. São Paulo: Cortez, 1995.

IANNI, O. A questão social. São Paulo em Perspectiva, São Paulo: Seade, v. 5, n. 1, 1991.

IBGE (Instituto Brasileiro de Geografia e Estatística). PNAD Contínua (Pesquisa Nacional por Amostra de Domicílio). 2018. Disponível em: https:/www.ibge.gov.br/estatisticas/ multidominio/condicoes-de-vida-desigualdade-e-pobreza/17270-pnad-continua.html. Acesso em: 5 out. 2020.

IPEA (Instituto de Pesquisa Econômica Aplicada). Sobre a recente queda da desigualdade de renda no Brasil: nota técnica. Brasília: IPEA, 2006.

IPEA (Instituto de Pesquisa Econômica Aplicada). A década inclusiva (2001-2011): desigualdade, pobreza e políticas de renda. Comunicados do IPEA, n. 155, 2012.

LACERDA, A. C. Distribuição de renda no Brasil nos anos 80. Revista de Economia Política, v. 14, n. 3, p. 134-140, jun./set. 1994.

LANGONI, C. Distribuição de renda e desenvolvimento econômico no Brasil. Rio de Janeiro: Expressão e Cultura, 1973.

MELO, M. R. B.; MONTE, P. A. Decomposição da renda domiciliar: uma análise regional. Rev. Econ. NE, Fortaleza, v. 46, n. 4, p. 137-153, out./dez. 2015.

NETTO, J. P. Cinco notas a propósito da questão social. Temporalis, 2. ed., ano 2, n. 3 (jan./ jul. 2001); Brasília: ABEPSS, 2004. p. 41-50.

ONU (Organização das Nações Unidas). PNUD (Programa das Nações Unidas para o Desenvolvimento). Além do rendimento, além das médias, além do presente: desigualdades no desenvolvimento humano no século XXI. Relatório do Desenvolvimento Humano (RDH), 2019. Disponível em: http://hdr.undp.org/sites/default/files/hdr_2019_pt.pdf. Acesso em: 5 out. 2020. 
PASTORINI, A. A categoria de "questão social" em debate. 3. ed. São Paulo: Cortez, 2010. PEREIRA, P. A. P. Questão social, Serviço Social e direitos de cidadania. Temporalis, 2. ed., ano 2, n. 3 (jan./jul. 2001); Brasília: ABEPSS, 2004. p. 51-62.

PIKETTY, T. A economia das desigualdades. Tradução: Pedro Elói Duarte. Coimbra: Conjuntura Actual, 2014.

ROSANVALLON, P. A nova questão social: repensando o Estado-providência. Brasília: Instituto Teotônio Vilela, 1998.

ROUSSEAU, J.-J. Discurso sobre a origem e os fundamentos da desigualdade entre homens (1754). Tradução: Maria Lacerda de Moura. [S. l.]: Ridendo Castigat Mores, 2001. Edição eletrônica. Disponível em: https://professordiegodelpasso.files.wordpress.com/2016/05/ jean-jackes-russeal-a-origem-da-desigualdade.pdf. Acesso em: 5 dez. 2020.

SANTOS, I. M. S. Questão social e Serviço Social no Brasil: fundamentos sócio-históricos. Cuiabá: EdUFMT, 2008.

SERRANO, F.; SUMMA, R. Política macroeconômica, crescimento e distribuição de renda na economia brasileira dos anos 2000. In: ENCONTRO INTERNACIONAL DA ASSOCIAÇÃO KEYNESIANA BRASILEIRA (AKB), 4 ., 3 a 5 ago. 2011, Rio de Janeiro. Anais [...]. Rio de Janeiro: AKB, 2011.

TELLES, V. S. Direitos sociais: afinal do que se trata? Belo Horizonte: Editora UFMG, 2006.

WANDERLEY, L. E. A questão social no contexto da "globalização": o caso latino-americano e o caribenho. In: BELFIORE-WANDERLEY, M.; BÓGUS, L.; YASBEK, M. C. (org.). Desigualdade e a questão social. São Paulo: EDUC, 1997. p. 51-162.

\section{Sobre as autoras}

Helena Lúcia Augusto Chaves - Doutora em Sociologia. Professora-associada. Departamento de Serviço Social.

E-mail: helena.chaves@gmail.com

Ana Cristina Brito Arcoverde - Doutora em Sociologia. Professora titular. E-mail: ana.arcoverde@gmail.com 